\title{
Prescription of antihypertensive agents in the treatment of hypertension in diabetic nephropathy patients on hemodialysis
}

\author{
Kalpana Bharani $^{1 *}$, Rubina Vohra ${ }^{2}$, Rajesh Bharani ${ }^{2}$, Chhaya Goyal $^{1}$, Pooja Reddy ${ }^{1}$
}

${ }^{1}$ Department of Pharmacology, Sri Aurobindo Medical College and PG Institute, Indore, Madhya Pradesh, India

${ }^{2}$ Department of Nephrology, Bombay Hospital, Indore, Madhya Pradesh, India

Received: 26 February 2021

Accepted: 02 April 2021

*Correspondence:

Dr. Kalpana Bharani,

Email: drkalpanabharani@gmail.com

Copyright: ( $)$ the author(s), publisher and licensee Medip Academy. This is an open-access article distributed under the terms of the Creative Commons Attribution Non-Commercial License, which permits unrestricted non-commercial use, distribution, and reproduction in any medium, provided the original work is properly cited.

\begin{abstract}
Background: All the patients with diabetic nephropathy have inherent hypertension and uncontrolled hypertension leads to deterioration in the kidney disease speedily. Aims and objectives were to analyze the prescription of antihypertensive agents in the treatment of hypertension in diabetic nephropathy patients on hemodialysis.

Methods: The study was conducted on diabetic nephropathy patients on maintenance hemodialysis, in Sri Aurobindo Institute of Medical Sciences, Indore (M.P.). We had included 73 diabetic nephropathy patients on maintenance hemodialysis, who provided their consent for participation in the study. Pearson coefficient of correlation was used for finding the correlation. Unpaired ' $t$ ' test was applied for intergroup mean comparison. A p value of $<0.05$ was taken as statistically significant.

Results: Total 73 diabetic nephropathy patients were included, with $80.8 \%$ being males. Mean age was $57.74 \pm 8.44$ years. Mean duration of dialysis was 32.06 \pm 35.84 months. Calcium channel blockers was given in $91.8 \%$ patients, followed by beta blockers in $61.6 \%$. Other antihypertensives used had lower prevalence. $65.8 \%$ patients required combination of 1-3 antihypertensives, $24.7 \%$ required 4-5 antihypertensives for control of hypertension. The mean number of antihypertensive medications was comparable between the two genders $(p>0.05)$. An inverse and statistically not significant correlation was seen between duration of dialysis; age and use of multiple antihypertensive medications $(\mathrm{p}>0.05)$.

Conclusions: A strong association has been reported by many between hypertension and diabetic nephropathy. It is imperative that hypertension is well controlled in all the patients of diabetic nephropathy. This will slow down the progression of kidney disease and improve the quality of life in patients with diabetic nephropathy.
\end{abstract}

Keywords: Hypertension, Diabetic nephropathy, Chronic kidney disease, Maintenance hemodialysis, Antihypertensive medication

\section{INTRODUCTION}

Diabetes mellitus type- 2 is a very common disease known to human kind and it in 1776 scientist Matthew Dobson identified that in diabetic patients, there is a presence of sugar in the urine. ${ }^{1}$ There is a mention of presence of characteristic sweet urine in patients with diabetes in our Indian medicine literature dating back to $300 \mathrm{BC}{ }^{2}$ Diabetes mellitus is characterized by three important symptoms - polyphagia, polyuria and polydipsia. At present China leads the foray of diabetes patients accounting for nearly 116 million people, which is closely followed by India with 77 million people, according to 2019 statistics. And it is expected that by 2045, India will be having around 134 million people with diabetes. ${ }^{3}$ The diabetic population of India has been found to have a higher insulin resistance, low BMI but with higher waist 
circumference, higher inflammatory markers and lower adiponectin levels. ${ }^{4}$

Along with the increase in diabetes mellitus, there has been a significant increase in the prevalence of diabetic nephropathy in these patients..$^{5}$ Diabetes has been now reported as the commonest cause of end-stage renal disease. $^{6}$

According to one of the studies, of all the chronic kidney disease seen in elderly, diabetic nephropathy accounts for no less than $46 \%{ }^{7}$

Nearly 800 persons per million populations is suffering from chronic kidney disease and approximately 150-200 persons per million are suffering from end-stage renal disease. $^{8}$

Hypertension has been found to be common among the patients suffering from chronic kidney disease and diabetes mellitus and is the leading cause of end-stage renal disease in the United States. ${ }^{9}$

Till date there is no clear consensus on the mechanism of hypertension in patients suffering from diabetic nephropathy and has been understood partially only. But this mechanism shows that there is excess of sodium retention, activation of sympathetic nervous system (SNS) and renin-angiotensin-aldosterone system (RAAS), increased oxidative stress and endothelial cell dysfunction (ECD). ${ }^{9}$

Chronic kidney disease can be linked to diabetes along with macroalbuminuria (>300 $\mathrm{mg} / 24$ hour) or microalbuminuria (30-300 mg/24 hour) with a history of diabetes mellitus of more than 10 years, as per the guidelines. ${ }^{10}$

Clinical evidence suggests that lowering blood pressure (BP) with antihypertensive drugs reduces the risk of myocardial infarction, stroke, heart failure, revascularization procedures and end-stage renal diseases in hypertensive patients. ${ }^{11}$

The management of the patients with chronic kidney disease on dialysis associated with hypertension and diabetes mellitus is both pharmacological and nonpharmacological, in combination with maintenance hemodialysis. Hypertension in these patients are generally treated with angiotensin converting enzyme inhibitors (ACE inhibitors) or angiotensin reception blockers (ARBs) and there are many other groups of medicines. Apart from just controlling hypertension, some of these medicines are also helpful in reducing the amount of urinary protein and thus slowing down the progression of diabetic nephropathy. ${ }^{12}$

The present study was undertaken to evaluate the pattern of management of hypertension in patients with chronic kidney disease and diabetes mellitus on hemodialysis.

\section{METHODS}

The present observational cross-sectional study was conducted in Sri Aurobindo Institute of Medical Sciences, Indore (M.P.) on patients with diabetic nephropathy on maintenance hemodialysis during the study period from 01 January 2018 to 31 March 2018. The approval to conduct the study was obtained from the Ethics Committee of our institution. Prior to the inclusion of any patient in the study, a voluntary written informed consent was taken. Being an observational study, no specific procedure or investigation was conducted for the study. All the data was obtained from the records of patient and captured in the proforma designed for the purpose of the study. Convenient sampling technique was used in the present study and we had included 73 patients with diabetic nephropathy on maintenance hemodialysis.

\section{Inclusion criteria}

All patients diagnosed to have chronic renal disease stage 5, undergoing treatment in Nephrology unit of this hospital ward. Patients and/or his/her legally acceptable representatives willing to provide their voluntary written informed consent for participation in the study.

\section{Exclusion criteria}

Children, Pregnant and lactating women, surgical conditions like kidney stone, tumors and trauma. Patients and/or his/her legally acceptable representatives not willing to provide their voluntary written informed consent for participation in the study.

The study was conducted with all the ethical considerations for conducting the research on humans. None of the personal information of the patients was used and only relevant data required for the research purpose was used. The rights and responsibilities of the patients were explained in detail. The data was analysed in Microsoft excel and descriptive statistics was presented in the form of tables. Comparison of mean drugs between the gender was done using Unpaired ' $t$ ' test. Correlation between two parameter variables was done using Pearson Coefficient of Correlation. A p value of $<0.05$ was taken as statistically significant.

\section{RESULTS}

The study had included 73 patients of either gender with diabetic nephropathy on maintenance dialysis to evaluate the pattern of use of antihypertensive medications to control blood pressure in these patients.

Majority of the patients were in the age group 41-60 years with a mean age of $57.74 \pm 8.44$ years. The youngest patient was 35 years and the oldest one was 79 years. Males constituted $80.8 \%$ of the study population. 
$34.2 \%$ patients were on dialysis for 1-6 months, $6.8 \%$ between 6-12 months, $16.4 \%$ between 13-24 months, $27.4 \%$ between $25-60$ months and $15.1 \%$ for more than 60 months. The mean duration of dialysis was $32.06 \pm 35.84$ months, ranging from 1 month to 164 months.

Table 1: Distribution according to antihypertensives given.

\begin{tabular}{|lll|}
\hline \multicolumn{2}{|c|}{ Number } & Percentage \\
\hline Calcium channel blockers & \\
\hline Nidedipine & 36 & 49.3 \\
\hline Amlodipne & 21 & 28.8 \\
\hline Clinidepin & 10 & 13.7 \\
\hline Beta blockers & & \\
\hline Metoprolol & 25 & 34.2 \\
\hline Atenolol & 5 & 6.8 \\
\hline Carvedilol & 15 & 20.5 \\
\hline Others & 0 & 0.0 \\
\hline ARTBs & & \\
\hline Losartan & 5 & 6.8 \\
\hline Telmisartan & 9 & 12.3 \\
\hline Olmesartan & 3 & 4.1 \\
\hline Others & 0 & 0.0 \\
\hline ACEIs & & \\
\hline Ramipril & 1 & 1.4 \\
\hline Enalapril & 0 & 0.0 \\
\hline Others & 0 & 0.0 \\
\hline Centrally acting & & \\
\hline Clonidine & 29 & 39.7 \\
\hline Mlaxonidine & 14 & 19.2 \\
\hline Minoxidil & 5 & 6.8 \\
\hline Alpha blockers & & \\
\hline Prazocin & 33 & 45.2 \\
\hline Doxazocin & 1 & 1.4 \\
\hline Diuretics & & 4.1 \\
\hline Furosemide & 3 & 5.5 \\
\hline Torsamide & 10 & \\
\hline Metalazone & & \\
\hline & & \\
\hline
\end{tabular}

The calcium channel blockers given were Nifedipine in $49.3 \%$ patients, Amlodepin in $28.8 \%$ patients and Clinidepin in $13.7 \%$ patients. Beta blockers given were Metoprolol in $34.2 \%$ patients, Atenolol in $6.8 \%$ patients and Carvedilol in $20.5 \%$ patients. ACE inhibitors given was Ramipril in $1.4 \%$ patients. ARTBs given were Losartan in $6.8 \%$ patients, Telmisartan in $12.3 \%$ patients and Olmesartan in $4.1 \%$ patients. The centrally acting drugs given were Clonidine in $39.7 \%$ patients, Maxonidine in $19.2 \%$ patients and Minoxidil in $6.8 \%$ patients. Alpha blockers given were Prazocin in $45.2 \%$ patients and Doxazocin in $1.4 \%$ patients. Diuretics given were Furosemide in $4.1 \%$ patients, Torsamide in $13.7 \%$ and Metalazone in $5.5 \%$ patients (Table 1).

Calcium channel blockers were used in $91.8 \%$ patients, followed by beta blockers in $61.6 \%$ patients.
In $2.7 \%$ patients only single drug was prescribed, in $65.8 \%$ patients 1-3 drug combinations were prescribed, in $24.7 \%$ patients 4-5 drug combinations were given and in $6.8 \%$ patients more than 5 drug combinations were prescribed in patients with diabetic nephropathy for the control of hypertension.

The mean number of drugs prescribed was comparable between males and females $(3.28 \pm 1.34$ in males versus $2.50 \pm 1.34$ in females, $\mathrm{p}>0.05)$.

Table 2: Comparison of mean number of drugs in relation to gender.

\begin{tabular}{|lllll|} 
Gender & Number & Mean \pm SD & $\begin{array}{l}\text { 't' } \\
\text { value }\end{array}$ & $\begin{array}{l}\text { P } \\
\text { value }\end{array}$ \\
\cline { 1 - 3 } Male & 59 & $3.29 \pm 1.34$ & 1.978, & 0.052, \\
Female & 14 & $2.50 \pm 1.34$ & $\mathrm{df}=71$ & NS \\
\hline
\end{tabular}

\section{Unpaired 't' test applied}

We found an inverse correlation between duration of dialysis and use of multiple antihypertensive medications ( $\mathrm{r}=-0.209)$, but this correlation was found to be statistically not significant $(\mathrm{p}=0.076)$.

We also found an inverse correlation between age and use of multiple antihypertensive medications ( $\mathrm{r}=\square 0.157$ ), but this correlation also was found to be statistically not significant $(\mathrm{p}=0.185)$.

\section{DISCUSSION}

The present study analysed the use of various antihypertensive medications in patients with diabetic nephropathy on maintenance dialysis.

There are many etiological factors contributing to the increase in blood pressure and hypertension in patients with diabetic nephropathy. The most common cause being that there is increased renal sodium reabsorption leading to volume expansion and also there is dysregulation of factors which regulate peripheral vascular resistance, which causes peripheral vasoconstriction. In these patients, hypertension is produced due to activation of RAAS, endothelin-1 upregulation, hyperactivation of reactive oxygen species with downregulation of nitric oxide (NO). ${ }^{9}$

There are evidences that confirm that in patients with diabetes mellitus, hypertension is already present, even before the patient is diagnosed with kidney disease. ${ }^{13}$ And duration of diabetes is independent of occurrence of hypertension. Hence, it becomes very important that hypertension be controlled in any of the patient having diabetes and will further complicate when the patient is diagnosed with kidney disease. ${ }^{9}$ And by the time patient reaches end-stage renal disease, the prevalence of hypertension in diabetic nephropathy patients is nearly $90 \%{ }^{14}$ All these factors make it imperative for the management of hypertension, especially in patients with 
diabetic nephropathy. And the goal of treatment should be control of diabetes, hypertension and reduction in albuminuria.

In our study male preponderance is seen, which is comparable to that reported by Joseph et al. ${ }^{15}$ Saju et al, reported an incidence of 33\% in the age group 51-60 years, which is quite comparable to our study, where we reported a highest prevalence of hypertension in the age group 41 60 years. $^{16}$

In $91.8 \%$ patients' calcium channel blockers are given and in $61.6 \%$ patients beta blockers are given, which are the commonest antihypertensives prescribed in the present study.

The calcium channel blockers are given in majority of the patients followed by beta blockers, alpha blockers, centrally acting drugs, ARTBs and diuretics in the decreasing order. ACE inhibitors has been found to slow the GFR degradation rate.

It is given in only small number of patients, as it is more preferable in patients with type- 1 diabetes mellitus, while our patients were mostly type-2 diabetes mellitus. A study supported that ACE inhibitors help in reducing albuminuria, preserving the renal function better than expected because of reduction in blood pressure in both type- 1 and type- 2 diabetic hypertensive patients. ${ }^{17}$

In many patients, the control of hypertension is not possible with the use of single drug, so many drugs in combination are given to control hypertension and have been found to be effective. Single drug was given in a small proportion of our patients, while majority of the patients received 1-3 drug combination, one-fourth of the patients received combination of 1-3 drugs and only a small proportion of patients received combination of more than 5 drugs.

The use of number of antihypertensive drugs is found to be independent of the gender of the patients. There is an inverse correlation between duration of dialysis; age and the use of multiple antihypertensive medications and was found to be statistically not significant.

The limitations of the study was that we had included only a small sample size of patients with diabetic nephropathy on maintenance hemodialysis and the outcome in terms of control of hypertension was included. We recommend that a large study taking diabetic nephropathy patients with / without hemodialysis be done and outcome in terms of blood pressure control, survival, etc. be also evaluated.

\section{CONCLUSION}

There is a strong association between diabetes and hypertension and chronic kidney disease. Studies have reported that better control of hypertension in patients with diabetic nephropathy has shown slowing of the progression of chronic kidney disease.
Calcium channel blockers are the most commonly used antihypertensives, followed by beta blockers and alpha blockers. Single antihypertensive drug was found to be effective in controlling hypertension in only a small proportion, while majority of the patients required a combination of more than one antihypertensive medication.

The use of number of antihypertensives was found to be independent of the gender of the patients and with the increase in duration of dialysis or age, the use of number of antihypertensive medications decreases in diabetic nephropathy patients on maintenance hemodialysis.

To conclude, it is imperative to control hypertension in patients with diabetic nephropathy as hypertension is seen in the diabetic patients well before they are diagnosed with chronic kidney disease.

\section{ACKNOWLEDGEMENTS}

We would like to thank all the institution for allowing us to conduct this study and the library for looking into the information related to the topic.

Funding: No funding sources

Conflict of interest: None declared

Ethical approval: The study was approved by the Institutional Ethics Committee

\section{REFERENCES}

1. Ritz E, Zeng X. Diabetic nephropathy - Epidemiology in Asia and the current state of treatment. Indian $\mathbf{J}$ Nephrol. 2011;21(2):75-84.

2. Frank LL. Diabetes mellitus in the texts of old Hindu medicine (Charaka, Susruta, Vagbhata). Am J Gastroenterol. 1957;27(1):76-95.

3. Elflein J. Number of people with diabetes, by country 2019. Available at: https://www.statista.com/statistics/281082/countrieswith-highest-number-of-

diabetics/\#: :text=Number\%20of\%20people\%20with $\% 20$ diabetes $\% 2 \mathrm{C} \% 20$ by $\% 20$ country $\% 202019 \&$ text $=$ China\%20is\%20the\%20country\%20with,134\%20mil lion\%20people\%20with\%20diabetes. Accessed on 15 August 2020.

4. Mohan V, Sandeep S, Deepa R, Shah B, Varghese C. Epidemiology of type 2 diabetes: Indian scenario. Indian J Med Res. 2007;125(3):217-30.

5. Pradeepa R, Anjana RM, Unnikrishnan R, Ganesan A, Mohan V, Rema M. Risk factors for microvascular complications of diabetes among South Indian subjects with type 2 diabetes--the Chennai Urban Rural Epidemiology Study (CURES) Eye Study-5. Diabetes Technol Ther. 2010;12(10):755-61.

6. Modi GK, Jha V. The incidence of end-stage renal disease in India: a population-based study. Kidney Int. 2006;70(12):2131-3. 
7. Prakash J, Hota JK, Singh S, Sharma OP. Clinical spectrum of chronic renal failure in the elderly: a hospital based study from eastern India. Int Urol Nephrol. 2006;38(3-4):821-7.

8. Agarwal SK, Srivastava RK. Chronic kidney disease in India: challenges and solutions. Nephron Clin Pract. 2009;111(3):c197-203.

9. Van Buren PN, Toto R. Hypertension in diabetic nephropathy: epidemiology, mechanisms, and management. Adv Chronic Kidney Dis. 2011;18(1):28-41.

10. KDOQI. KDOQI Clinical Practice Guidelines and Clinical Practice Recommendations for Diabetes and Chronic Kidney Disease. Am J Kidney Dis. 2007;49(2 Suppl 2):S12-154.

11. James PA, Oparil S, Carter BL, Eighth Joint National Committee (JNC 8) Members et al. 2014 evidencebased guideline for the management of high blood pressure in adults: report from the panel members appointed to the Eighth Joint National Committee (JNC 8), Supplemental Content. JAMA. 2014;311:507-20.

12. Diabetic nephropathy. Available at: https://www.mydr.com.au/diabetes/diabeticnephropathy\#: :text=Diabetic\%20nephropathy\%20(d iabetic\%20kidney\%20disease,lets\%20protein\%20int o\%20your\%20urine. Accessed on 15 August 2020.
13. Ismail N, Becker B, Strzelczyk P, Ritz E. Renal disease and hypertension in non-insulin-dependent diabetes mellitus. Kidney Int. 1999;55(1):1-28.

14. Bakris GL, Williams M, Dworkin L, Elliott WJ, Epstein M, Toto R, et al. Preserving renal function in adults with hypertension and diabetes: a consensus approach. National Kidney Foundation Hypertension and Diabetes Executive Committees Working Group. Am J Kidney Dis. 2000;36(3):646-61.

15. Joseph N, Yogananda R, Bharathi DR, Padman V, Sandeep GN. A study on prescription pattern of antihypertensive agents in chronic renal failure patients and assessment of medication adherence. Int $\mathbf{J}$ Pharm Sci Rev Res. 2017;45(2):72-5.

16. Saju AP, Edakkarayil AC, Maheswari E, Gurudev KC. Prescribing pattern and cost effectiveness analysis of antihypertensive drugs in chronic kidney disease patients. EJPMR. 2016;3(1):219-25.

17. Kasiske BL, Kalil RS, Ma JZ, Liao M, Keane WF: Effect of antihypertensive therapy on the kidney in patients with diabetes: a meta-regression analysis. Ann Intern Med. 1993;118:129-38.

Cite this article as: Bharani $\mathrm{K}$, Vohra $\mathrm{R}$, Bharani $\mathrm{R}$, Goyal C, Reddy P. Prescription of antihypertensive agents in the treatment of hypertension in diabetic nephropathy patients on hemodialysis. Int J Basic Clin Pharmacol 2021;10:495-9. 